\title{
Estimated Prevalence of Heterozygous Familial Hypercholesterolemia in Patients With Acute Coronary Syndrome Multicenter Registration Study in Japan
}

\author{
Hirotoshi Ohmura, ${ }^{1}$ MD, Yoshifumi Fukushima, ${ }^{1}$ MD, Atsushi Mizuno, ${ }^{2}$ MD, \\ Koichiro Niwa, ${ }^{2} \mathrm{MD}$, Yohei KobaYASHI, ${ }^{3} \mathrm{MD}$, Toshiaki Ebina, ${ }^{4} \mathrm{MD}$, \\ Kazuo Kimura, ${ }^{4} \mathrm{MD}$, Shun Ishibashi, ${ }^{5} \mathrm{MD}$, and Hiroyuki Daida, ${ }^{1} \mathrm{MD}$, \\ on behalf of the Research Committee on Primary Hyperlipidemia \\ of the Ministry of Health and Welfare of Japan
}

\begin{abstract}
SUMMARY
Heterozygous familial hypercholesterolemia $(\mathrm{FH})$ represents a strong risk for development of premature coronary artery disease (CAD). However, the majority of patients with FH are undiagnosed and the prevalence likely represents an underestimate in most countries. In Japan, the possible contribution of FH to the development of CAD may be higher because of the low incidence of CAD among the general population. We estimated the prevalence of heterozygous FH by measuring Achilles tendon thickness (ATT) in patients with acute coronary syndrome (ACS).

A total of 359 patients suffering from ACS were enrolled in this multicenter registration study. Heterozygous FH was defined according to the diagnostic criteria proposed by the Japan Atherosclerosis Society. After excluding 63 patients because of missing ATT data or plasma triglyceride levels that were $4.5 \mathrm{mmol} / \mathrm{L}$ or more, 296 patients were eligible for inclusion in the study. The number of patients with ATT of $9 \mathrm{~mm}$ or more was $53(17.9 \%)$. They were significantly younger and had significantly higher LDL cholesterol levels than patients with an ATT less than $9 \mathrm{~mm}$. The prevalence of heterozygous $\mathrm{FH}$ was 5.7\% (1/17.5) and more prominent in younger patients who were less than 60 years old (7.8\%). In patients with ATT of $9 \mathrm{~mm}$ or more, approximately 1 in 3.5 fulfilled the criteria for heterozygous FH.

We demonstrated the usefulness of measuring ATT by radiography and the high prevalence of heterozygous FH in patients with ACS in Japan, especially in younger patients who were less than 60 years old. (Int Heart J 2017; 58: 88-94)
\end{abstract}

Key words: Premature coronary artery disease, LDL cholesterol, Achilles tendon thickness

$\mathrm{F}$ amilial hypercholesterolemia $(\mathrm{FH})$ is one of the most common inherited metabolic diseases and is characterized by severely elevated plasma low-density lipoprotein (LDL) cholesterol levels. Most common inheritance is an autosomal dominant disorder caused by a mutation of the gene for the LDL receptor (LDLR). ${ }^{1-5)}$ To date, 3 other gene mutations in the LDLR pathway have been discovered, including apolipoprotein B, proprotein convertase subtilisin kexin type 9 (PCSK9), or LDLR adaptor protein 1 (LDLRAP1).

The prevalence of the heterozygous $\mathrm{FH}$ has been estimated at 1/200-1/500 and of homozygous FH at 1/160,000$1 / 1,000,000 .^{3-6)}$ However, the prevalence likely represents an underestimate in most countries because of a majority of patients with FH are undiagnosed. ${ }^{4,7}$ The risk of premature coronary artery disease (CAD) is elevated to about 20 -fold in het- erozygous FH. Regarding the natural course of heterozygous $\mathrm{FH}$ patients, around $50 \%$ of men experienced adverse cardiac events by the age of 50 years and $30 \%$ of females by the age of 60 years. ${ }^{4)}$ Nevertheless, it is necessary to perform more appropriate diagnosis and intensive cholesterol-lowering therapy to prevent the development of premature $\mathrm{CAD},{ }^{8}$ the majority of patients with $\mathrm{FH}$ are either underdiagnosed or undertreated.

Editorial p.1

In Japan, the possible contribution of FH to the development of CAD may be higher because of the low incidence of CAD among the general population. Most individuals and families with FH may simply be overlooked among the huge number of patients with any CAD caused by more common risk factors. ${ }^{9)}$ In particular, we expect the high prevalence of

From the ${ }^{1}$ Department of Cardiovascular Medicine, Juntendo University Graduate School of Medicine, ${ }^{2}$ Department of Cardiology, St. Luke's International Hospital, Tokyo, ${ }^{3}$ Department of Cardiology, Kokura Memorial Hospital, Fukuoka, ${ }^{4}$ Department of Cardiovascular Center, Yokohama City University Medical Center, Kanagawa, and ${ }^{5}$ Division of Endocrinology and Metabolism, Department of Internal Medicine, School of Medicine, Jichi Medical University, Tochigi, Japan.

This study was supported by the Scientific Research Fund from the Ministry of Health, Labor and Welfare of Japan (201324014A, on the work of the Research Commitee on Primary Hyperlipidemia. Chairman: Shun Ishibashi, MD, Division of Endocrinology and Metabolism, Department of Internal Medicine, School of Medicine, Jichi Medical University).

Address for correspondence: Hirotoshi Ohmura, MD, Department of Cardiovascular Medicine, Juntendo University Graduate School of Medicine, 2-1-1 Hongo, Bunkyo-ku, Tokyo 113-8421, Japan. E-mail: hohmura@juntendo.ac.jp

Received for publication April 19, 2016. Revised and accepted June 17, 2016.

Released in advance online on J-STAGE January 24, 2017.

All rights reserved by the International Heart Journal Association. 
maximum thickness of $9 \mathrm{~mm}$ or more. ${ }^{13)}$ Body mass index (BMI) was calculated as weight in kilograms divided by height in meters squared $\left(\mathrm{kg} / \mathrm{m}^{2}\right)$. Smoking status was classified into never, current, and former smoking. Current smoking was defined as positive by having a smoking habit within 1 year before admission. Hypertension was defined as the use of antihypertensive drugs or a usual blood pressure level either higher than $140 \mathrm{mmHg}$ for systolic or $90 \mathrm{mmHg}$ for diastolic or both. Diabetes mellitus was defined as the use of hypoglycemic agents or according to the Evidence-based Practice Guideline for the Treatment for Diabetes in Japan 2013. ${ }^{22)}$ A history of CAD was defined as previous myocardial infarction or any coronary revascularization for myocardial ischemia. Cerebrovascular disease (CVD) was defined as previous stroke or transient ischemic attack (TIA). A family history of CAD was defined as positive by having within 2nd degree family members. Biochemical analysis: Plasma lipid and lipoprotein levels were measured as soon as possible when subjects were admitted irrespective of food intake. Cholesterol and triglyceride levels were measured by enzymatically using an automated analyzer in the clinical laboratories of each hospital. If possible, we obtained previous LDL cholesterol values before a prescribed statin or admission from medical records. LDL cholesterol was usually calculated using the Friedewald equation, however, we adopted LDL cholesterol values measured by the direct method if total cholesterol levels were not available.

Diagnosis of heterozygous familial hypercholesterolemia: Heterozygous FH was defined according to the diagnostic criteria for heterozygous FH in adults proposed by JAS as follows: 1) hyper-LDL cholesterolemia [an untreated LDL cholesterol level of $>4.65 \mathrm{mmol} / \mathrm{L}(180 \mathrm{mg} / \mathrm{dL})]$, 2) tendon xanthomas (tendon xanthoma on backs of the hands, elbows, knees, or elsewhere, or Achilles tendon thickening) or xanthoma tuberosum, and 3) family history of FH or premature CAD (within a patient's 2nd degree relatives). ${ }^{20)}$ If a patient meets two or 3 of the above-mentioned criteria, the condition should be diag- nosed as heterozygous $\mathrm{FH}$.

Statistical analysis: Continuous variables are presented as the mean \pm standard deviation. Categorical data are presented as numbers and percentages. Unpaired Student's $t$-test and oneway analysis of variance (ANOVA) were used to assess differences in continuous variables between groups. Differences in categorical variables were assessed by the $\chi^{2}$-test. A $P$ value $<$ 0.05 was considered significant. All statistical analyses were performed using JMP 10 software (2012, SAS Institute Inc., Cary, NC, USA).

\section{RESULTS}

Patient clinical characteristics with ACS: Among a total of consecutive 359 patients suffering from ACS, 63 were excluded because of missing ATT data or plasma triglyceride (TG) levels that were $4.5 \mathrm{mmol} / \mathrm{L}$ (400 $\mathrm{mg} / \mathrm{dL})$ or more. Consequently, 296 patients were eligible for inclusion in the present study. None of these patients had been diagnosed as heterozygous FH nor did they have a family history of FH in relatives. The clinical characteristics of the ACS patients who participated in this study are shown in Table I. The mean age of the subjects was $64 \pm 13$ years old and was significantly higher in women than in men. BMI and the prevalence of smokers and diabetes mellitus were significantly higher in men than in women. A history of CAD was present in 19 patients $(6.4 \%)$ and $6(2.0 \%)$ patients had CVD, however, there was no significant difference between men and women. Statins were being taken by only $23.3 \%$ of the subjects and the trends for men and women were similar. The plasma level of HDL cholesterol in women was significantly higher than that in men, however, there were no significant differences in the plasma levels of LDL cholesterol and TG. Concerning the clinical diagnosis of ACS, about two-thirds of the patients developed STEMI and there were no significant differences in the prevalence of clini-

Table I. Clinical Characteristics of ACS Patients in This Study

\begin{tabular}{|c|c|c|c|}
\hline & All & Men & Women \\
\hline Number & 296 & 235 & 61 \\
\hline Age (years) & $64 \pm 13$ & $63 \pm 13$ & $72 \pm 10^{* * *}$ \\
\hline BMI $\left(\mathrm{kg} / \mathrm{m}^{2}\right)$ & $24.2 \pm 3.6$ & $24.5 \pm 3.4$ & $23.2 \pm 3.9^{*}$ \\
\hline \multicolumn{4}{|l|}{ Smoking $(\%)^{* * *}$} \\
\hline Never & $80(27.0)$ & 45 (19.2) & $35(57.4)$ \\
\hline Current & $124(41.9)$ & $107(45.5)$ & $17(27.9)$ \\
\hline Former & $92(31.1)$ & $83(35.3)$ & $9(14.8)$ \\
\hline Hypertension (\%) & $179(60.5)$ & $143(60.9)$ & $36(59.0)$ \\
\hline Diabetes mellitus (\%) & $102(34.5)$ & $84(35.7)$ & $18(29.5)^{*}$ \\
\hline Previous CAD (\%) & $19(6.4)$ & $17(7.2)$ & $2(3.3)$ \\
\hline Previous CVD (\%) & $6(2.0)$ & $3(1.3)$ & $3(4.9)$ \\
\hline LDL-C (mmol/L) & $3.13 \pm 1.03$ & $3.08 \pm 1.03$ & $3.26 \pm 1.01$ \\
\hline HDL-C (mmol/L) & $1.16 \pm 0.31$ & $1.14 \pm 0.28$ & $1.29 \pm 0.31^{* *}$ \\
\hline $\mathrm{TG}(\mathrm{mmol} / \mathrm{L})$ & $1.40 \pm 0.88$ & $1.43 \pm 0.89$ & $1.24 \pm 0.79$ \\
\hline Statin administration (\%) & $69(23.3)$ & $55(23.4)$ & $14(23.0)$ \\
\hline $\operatorname{ATT}(\mathrm{mm})$ & $7.7 \pm 1.7$ & $7.8 \pm 1.6$ & $7.4 \pm 1.8$ \\
\hline $\operatorname{STEMI}(\%)^{*}$ & $208(60.5)$ & $166(60.6)$ & $42(60.0)$ \\
\hline NSTEMI (\%) & $57(16.6)$ & $51(18.6)$ & $6(8.6)$ \\
\hline $\operatorname{UAP}(\%)$ & $79(23.0)$ & $57(20.8)$ & $22(31.4)$ \\
\hline
\end{tabular}

Data are expressed as the mean $\pm \mathrm{SD},{ }^{*} P<0.05,{ }^{* *} P<0.005,{ }^{* * *} P<0.0001$. ACS indicates acute coronary syndrome; BMI, body mass index; CAD, coronary artery disease; CVD, cerebrovascular disease; LDL-C, low-density lipoprotein cholesterol; HDL-C, high-density lipoprotein cholesterol; TG, triglycerides; ATT, Achilles tendon thickening; STEMI, ST elevation myocardial infarction; NSTEMI, non-ST elevation myocardial infarction; and UAP, unstable angina pectoris. 
cal diagnosis of ACS between men and women.

Achilles tendon thickness (ATT): The mean ATT measured by radiography was $7.7 \pm 1.7 \mathrm{~mm}$ and there was no significant difference between men and women. ATT demonstrated a very weak but significant positive correlation with plasma levels of LDL cholesterol $\left(r^{2}=0.033, P=0.0016\right)$ and a negative correlation with age $\left(r^{2}=0.023, P=0.0092\right)$.

Patient clinical characteristics classified by ATT: We evaluated the clinical characteristics classified by ATT (Table II). The number of patients with ATT of $9 \mathrm{~mm}$ or more was 53 $(17.9 \%)$. They were significantly younger and had significantly higher LDL cholesterol levels and significantly lower HDL cholesterol levels than patients with an ATT less than $9 \mathrm{~mm}$. The distribution of plasma LDL cholesterol in patients with ATT of $9 \mathrm{~mm}$ or more was varied and asymmetric, although those in patients with ATT less than $9 \mathrm{~mm}$ were almost normal and symmetric (Figure 2). We did not observe any significant differences in other coronary risk factors, sex, or even in the percentage of subjects taking a statin. The percentage of patients with a family history of premature CAD was almost double in patients with ATT of $9 \mathrm{~mm}$ or more compared with patients with ATT less than $9 \mathrm{~mm}$, although there was no statistically significant difference (Table III).

Estimated prevalence of heterozygous familial hypercholesterolemia: The prevalences of hyper-LDL cholesterolemia [LDL cholesterol $\geq 4.65 \mathrm{mmol} / \mathrm{L}(180 \mathrm{mg} / \mathrm{dL})]$ and definite heterozygous FH according to the diagnostic criteria of JAS were significantly higher in patients with ATT of $9 \mathrm{~mm}$ or more than in those patients with ATT less than $9 \mathrm{~mm}$ (17.0\% versus $4.9 \%$; $P<0.005$ and $28.3 \%$ versus $0.8 \% ; P<0.0001)$. Approximately 1 in 3.5 subjects with ATT of $9 \mathrm{~mm}$ or more might be heterozygous FH among patients suffering from ACS. In all patients, the prevalence of definite heterozygous FH was 5.7\% (1 in 17.5).

Clinical characteristics of heterozygous familial hypercholesterolemia: To compare the ATT or prevalence of heterozygous FH by age, we divided the subjects into two groups; those 60 years old or more and those less than 60 years old (Table IV). Both the percentage of ATT of $9 \mathrm{~mm}$ or more and definite heterozygous $\mathrm{FH}$ were more prominent in the patients less than
60 years old than in those more than 60 years old $(23.5 \%$ versus $14.9 \%, 7.8 \%$ versus $4.6 \%$; respectively, $P=\mathrm{NS}$ ). This result suggested that 1 in 12.8 patients less than 60 years old suffering from ACS might possibly be heterozygous FH. This trend was observed in both men and women regarding the prevalence of ATT of $9 \mathrm{~mm}$ or more. However, we could not confirm this trend regarding the prevalence of heterozygous $\mathrm{FH}$, because there were no female patients less than 60 years old with heterozygous $\mathrm{FH}$.

\section{DiscuSsion}

Our study demonstrated that the prevalence of definite heterozygous FH based on the diagnostic criteria of the JAS guideline was estimated to be $5.7 \%$ (one in 17.5) among patients suffering from ACS by measuring ATT. The prevalence of heterozygous FH was more prominent in patients less than

Table II. Clinical Characteristics Classified by ATT

\begin{tabular}{lcc}
\hline & ATT $\geq 9$ & ATT $<9$ \\
\hline Number (\%) & $53(17.9)$ & $243(82.1)$ \\
Age (years) & $61 \pm 13^{*}$ & $65 \pm 13$ \\
Men (\%) & $46(86.8)$ & $189(77.8)$ \\
BMI $\left(\mathrm{kg} / \mathrm{m}^{2}\right)$ & $24.6 \pm 3.5$ & $24.2 \pm 3.6$ \\
Smoking $(\%)$ & & \\
$\quad$ Never & $12(22.6)$ & $68(28.0)$ \\
Current & $26(49.1)$ & $98(40.3)$ \\
$\quad$ Former & $15(28.3)$ & $77(31.7)$ \\
Hypertension $(\%)$ & $28(52.8)$ & $25(62.1)$ \\
Diabetes mellitus $(\%)$ & $20(37.7)$ & $82(33.7)$ \\
Previous CAD $(\%)$ & $2(3.8)$ & $16(6.6)$ \\
Previous CVD $(\%)$ & $0(0.0)$ & $7(2.9)$ \\
LDL-C (mmol/L) & $3.49 \pm 1.29^{*}$ & $3.05 \pm 0.96$ \\
HDL-C (mmol/L) & $1.09 \pm 0.23^{*}$ & $1.19 \pm 0.31$ \\
TG (mmol/L) & $1.59 \pm 0.98$ & $1.35 \pm 0.85$ \\
Statin administration $(\%)$ & $11(20.8)$ & $58(23.9)$ \\
\hline
\end{tabular}

Data expressed as the mean $\pm \mathrm{SD},{ }^{*} P<0.05,{ }^{* *} P<0.005,{ }^{* * *} P<0.0001$. $\mathrm{BMI}$ indicates body mass index; CAD, coronary artery disease; CVD, cerebrovascular disease; LDL-C, low-density lipoprotein cholesterol; HDL, high-density lipoprotein cholesterol; and TG, triglycerides.

\section{Mean LDL cholesterol}

\section{$3.49 \pm 1.29(\mathrm{mmo} / \mathrm{L})$}

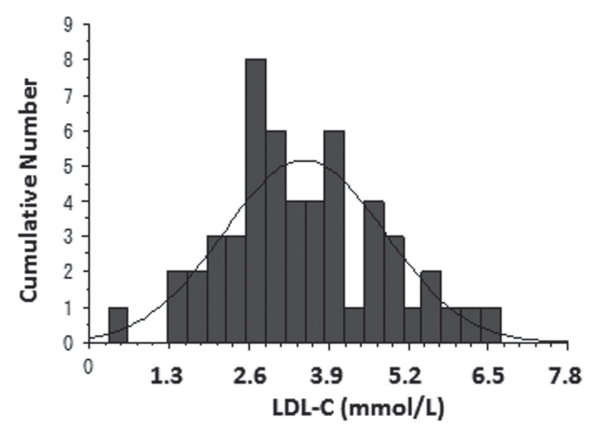

ATT $\geq 9$

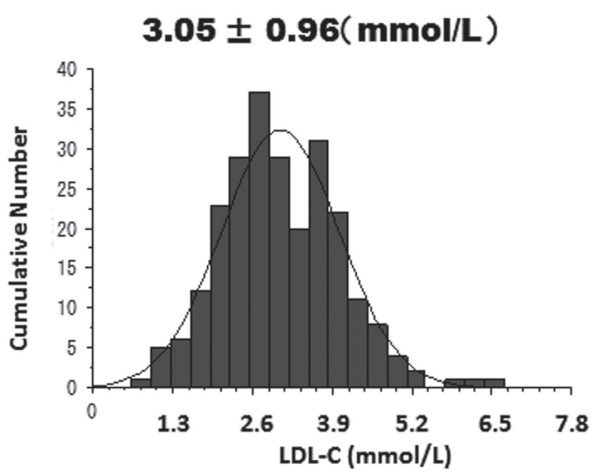

ATT $<9$

Figure 2. Distribution of plasma LDL cholesterol classified by ATT. LDL indicates low-density lipoprotein; and ATT, Achilles tendon thickening. 
Table III. Clinical Characteristics Classified by ATT

\begin{tabular}{lrrr}
\hline & All & ATT $\geq 9$ & ATT $<9$ \\
\hline STEMI $(\%)$ & $208(60.5)$ & $35(66.0)$ & $155(63.8)$ \\
NSTEMI $(\%)$ & $57(16.6)$ & $7(13.2)$ & $41(16.9)$ \\
UAP $(\%)$ & $79(23.0)$ & $11(20.8)$ & $47(19.3)$ \\
Family history of premature CAD (\%) & $23(7.8)$ & $7(13.2)$ & $16(6.6)$ \\
ATT (mm) & $7.7 \pm 1.7$ & $10.4 \pm 1.6$ & $7.1 \pm 0.9^{* * *}$ \\
LDL-C $\geq 4.65$ mmol/L $(\%)$ & $21(7.1)$ & $9(17.0)$ & $12(4.9)^{* *}$ \\
Definite heterozygous FH According to JAS GL $(\%)$ & $17(5.7)$ & $15(28.3)$ & $2(0.8)^{* * *}$ \\
\hline
\end{tabular}

Data expressed as the mean $\pm \mathrm{SD},{ }^{*} P<0.05,{ }^{* *} P<0.005,{ }^{* * *} P<0.0001$. STEMI indicates ST elevation myocardial infarction; NSTEMI, non-ST elevation myocardial infarction; UAP, unstable angina pectoris; CAD, coronary artery disease; ATT, Achilles tendon thickening; LDL-C, low-density lipoprotein cholesterol; FH, familial hypercholesterolemia; JAS, Japanese Atherosclerosis Society; and GL, guideline.

Table IV. Stratification by Age of 60 Years Old Among Patients With ACS

\begin{tabular}{cccc}
\hline & $<60$ years & $\geq 60$ years & All \\
\hline ATT $\geq 9$ mm $^{*}(\%)$ & 23.5 & 14.9 & 17.9 \\
Men/Women (\%) & $23.7 / 20.0$ & $16.7 / 10.7$ & $19.6 / 11.5$ \\
Heterozygous FH (\%) & 7.8 & 4.6 & 5.7 \\
Men/Women (\%) & $8.2 / 0$ & $4.3 / 5.4$ & $6.0 / 4.9$ \\
\hline
\end{tabular}

ACS indicates acute coronary syndrome; ATT, Achilles tendon thickening; and FH, familial hypercholesterolemia.

60 years old (one in 12.8), especially in men. Even in cases of no lipid-lowering therapy, it was reported that approximately $30 \%$ of women experienced adverse cardiac events by the age of 60 . $^{4}$ Thus, it was not surprising that there were no heterozygous FH patients who were less than 60 years old in this study. The present results suggest that more careful examination should be encouraged for the adequate care of patients with ACS. The high prevalence of heterozygous FH in patients with ACS, especially in younger patients, is consistent with previous data reported by Goldstein. ${ }^{23)}$ However, there is little data concerning the prevalence of potential $\mathrm{FH}$ among patients with established CAD. In a series of consecutive patients less than 60 years old who were admitted with an acute myocardial infarction in 1995, 36 of 292 had FH (12.3\%). ${ }^{10)}$ Recently, EUROASPIRE IV data also demonstrated that the prevalence of potential $\mathrm{FH}$ in patients with acute coronary events was $8.3 \%$ ( 1 in 12$)$, and more in men less than 50 years old $(22 \%){ }^{24)}$

The possible contribution of FH to CAD might be higher even in Japanese because of the low prevalence of CAD among the general Japanese population. However, it is difficult to diagnose heterozygous FH in patients with ACS because of increasing cholesterol catabolism and the fact that they take statins just after the onset of ACS. In addition, the range of plasma LDL cholesterol levels in FH overlaps with that of people with non-genetic polygenic hypercholesterolemia. ${ }^{12,25)}$ On the other hand, tendon xanthomas are strongly associated with a genetic diagnosis and highly specific for FH patients. ${ }^{12)}$ Achilles tendon xanthomas in particular have been used as one of the criteria for the clinical diagnosis of FH in JAS and the Simon Broome Register because of their high sensitivity and specificity. ${ }^{1,26)}$ A strongly positive correlation was observed between ATT and cholesterol-year scores in $\mathrm{FH}^{27,28)}$ Our findings that patients with ATT of $9 \mathrm{~mm}$ or more had significantly higher levels of plasma LDL cholesterol and percentage of hyperLDL cholesterolemia [LDL cholesterol $\geq 4.65 \mathrm{mmol} / \mathrm{L}$ (180 $\mathrm{mg} / \mathrm{dL})]$ are consistent with previous reports. ${ }^{27-29)}$ Approximately 1 in 3.5 patients with ATT of $9 \mathrm{~mm}$ or more who ful- filled the diagnostic criteria of heterozygous $\mathrm{FH}$, suggesting that ATT is a good marker for evaluating heterozygous FH. We should consider the possibility that patients with ATT of $9 \mathrm{~mm}$ or more suffering from ACS have heterozygous FH.

In addition, the percentage of patients with a family history of premature CAD was double in patients with ATT of 9 $\mathrm{mm}$ or more compared to those of less than $9 \mathrm{~mm}$. As an autosomal dominant disorder, $50 \%$ of siblings and children are likely to inherit this condition. Therefore, we should make an effort to gather more details concerning their relatives in 2nd generation pedigrees in possible cases. Cascade testing is an essential part of evaluating heterozygous FH and of any costeffective prevention program for CAD risk reduction in patients with heterozygous $\mathrm{FH}$, especially among children and adolescence. ${ }^{20,32-35)}$ A careful family history, with regard to cholesterol levels (if known), and age of onset of CAD should be collected. The key responsibility of the cardiologist is to screen for FH through a family history, physical examination, and basic lipid profile. ${ }^{36)}$ Once diagnosed, heterozygous FH patients can readily be treated with cholesterol-lowering medication to attenuate the development of atherosclerosis and prevent the development of CAD. ${ }^{37-41)}$

Study limitations: This study had several limitations. First, the possibility of underdiagnosing heterozygous $\mathrm{FH}$ in patients with ACS cannot be denied because we found a considerable number of patients with ATT of $9 \mathrm{~mm}$ or more without diagnosing heterozygous FH. Second, the collection of blood samples varied depending on the facility and on the arrival time at the hospital. It was difficult to adopt the use of levels of LDL cholesterol as diagnosis criteria for heterozygous FH. This might be explained, in part, by differences in the prevalence of heterozygous FH between our study and previous studies. Third, we did not perform genetic molecular analysis to identify monogenic mutations associated with FH. However, the aim of our study was to estimate the prevalence of clinical FH according to the criteria of the JAS for the diagnosis of heterozygous FH. 
Conclusion: We demonstrated a high prevalence of heterozygous FH in patients with ACS, especially in younger patients less than 60 years old. ATT is a good practical marker for evaluating a high risk population of heterozygous $\mathrm{FH}$ in patients with ACS. The measurement of ATT by radiography should be used not only as a diagnostic criteria for heterozygous $\mathrm{FH}$, but also, perhaps more importantly, as a prognostic factor in high risk patients who need a more aggressive approach.

\section{ACKNOWLEDGMent}

The authors thank Ms. Yukie Ochi of the Department of Cardiology, Kokura Memorial Hospital, and also Ms. Megumi Matsumoto of the Department of Cardiovascular Medicine, Juntendo University, for their excellent technical support.

\section{Disclosure}

Conflict of interest: There are no conflicts of interest to declare.

\section{REFERENCES}

1. Goldstein JL, Hobbs HH, Brown MS. Familial hypercholesterolemia. In: Scriver CR, Beaudet AL, Sly WS, Valle D, eds. The Metabolic and Molecular Bases of Inherited Disease. 8th ed. New York, NY: McGraw-Hill; 2001: 2863-913.

2. Goldstein JL, Dana SE, Brunschede GY, Brown MS. Genetic heterogeneity in familial hypercholesterolemia: evidence for two different mutations affecting functions of low-density lipoprotein receptor. Proc Nat Acad Sci U S A 1975; 72: 1092-6.

3. Mabuchi H, Nohara A, Noguchi T, et al. Molecular genetic epidemiology of homozygous familial hypercholesterolemia in the Hokuriku district of Japan. Atherosclerosis 2011; 214: 404-7.

4. Nordestgaard BG, Chapman MJ, Humphries SE, et al; European Atherosclerosis Society Consensus Panel. Familial hypercholesterolaemia is underdiagnosed and undertreated in the general population: guidance for clinicians to prevent coronary heart disease: consensus statement of the European Atherosclerosis Society. Eur Heart J 2013; 34: 3478-90a.

5. Benn M, Watts GF, Tybjaerg-Hansen A, Nordestgaard BG. Familial hypercholesterolemia in the Danish general population: prevalence, coronary artery disease, and cholesterol-lowering medication. J Clin Endocrinol Metab 2012; 97: 3956-64.

6. Sjouke B, Kusters DM, Kindt I, et al. Homozygous autosoma dominant hypercholesterolemia in the Netherlands: prevalence, genotype-phenotype relationship, and clinical outcome. Eur Heart J 2015; 36: 560-5.

7. Watts GF, Lewis B, Sullivan DR. Familial hypercholesterolemia: a missed opportunity in preventive medicine. Nat Clin Pract Cardiovasc Med 2007; 4: 404-5

8. Masuda J, Tanigawa T, Yamada T, et al. Effect of combination therapy of ezetimibe and rosuvastatin on regression of coronary atherosclerosis in patients with coronary artery disease. Int Heart J 2015; 56: 278-85.

9. Daida H, Teramoto T, Kitagawa Y, Matsushita Y, Sugihara M. The relationship between low-density lipoprotein cholesterol levels and the incidence of cardiovascular disease in high-risk patients treated with pravastatin: main results of the APPROACH-J study. Int Heart J 2014; 55: 39-47.

10. Dorsch MF, Lawrance RA, Durham NP, Hall AS. Familial hypercholesterolemia is underdiagnosed after AMI. BMJ 2001; 322: 111.
11. Genest JJ Jr, Martin-Munley SS, McNamara JR, et al. Familial lipoprotein disorders in patients with premature coronary artery disease. Circulation 1992; 85: 2025-33.

12. Civeira F, Ros E, Jarauta E, et al. Comparison of genetic versus clinical diagnosis in familial hypercholesterolemia. Am J Cardiol 2008; 102: 1187-93.

13. Mabuchi H, Ito S, Haba T, Ueda K, Ueda R. Discrimination of familial hypercholesterolemia and secondary hypercholesterolemia by Achilles' tendon thickness. Atherosclerosis 1977; 28: 61-8.

14. MEDPED (Make Early Diagnosis to Prevent Early Deaths) US Program. Available at: http://www.medped.org/ Accessed November 11, 2016.

15. Watts GF, Gidding S, Wierzbicki AS, et al. Integrated guidance on the care of familial hypercholesterolaemia from the International FH Foundation. Int J Cardiol 2014; 171: 309-25. (Review)

16. Hopkins PN, Toth PP, Ballantyne CM, Rader DJ; National Lipid Association Expert Panel on Familial Hypercholesterolemia. Familial hypercholesterolemias: prevalence, genetics, diagnosis and screening recommendations from the National Lipid Association Expert Panel on Familial Hypercholesterolemia. J Clin Lipidol 2011; 5: S9-17.

17. Risk of fatal coronary heart disease in familial hypercholesterolaemia. Scientific Steering Committee on behalf of the Simon Broome Register Group. BMJ 1991; 303: 893-6.

18. Wierzbicki AS, Humphries SE, Minhas R; Guideline Development Group. Familial hypercholesterolaemia: summary of NICE guidance. BMJ 2008; 337: a1095.

19. World Health Organization. Familial hypercholesterolemia - report of a second WHO Consultation. Geneva, Switzerland: World Health Organization, 1999. (WHO publication no. WHO/HGN/ FH/CONS/99.2). Available at: http://apps.who.int/iris/bitstream/ 10665/66346/1/WHO_HGN_FH_CONS_99.2.pdf Accessed November 11, 2016.

20. Harada-Shiba M, Arai H, Oikawa S, et al. Guidelines for the management of familial hypercholesterolemia. J Atheroscler Thromb 2012: 19; 1043-60.

21. Thygesen K, Alpert JS, Jaffe AS, et al; Joint ESC/ACCF/AHA/ WHF Task for Universal Definition of Myocardial Infarction. Third universal definition of myocardial infarction. J Am Coll Cardiol 2012; 60: 1581-98.

22. Haneda M. 110th Scientific Meeting of the Japanese Society of Internal Medicine: Symposium: 3. Social impacts and controversial points of clinical practice guidelines; 1) Overview of guidelines: concepts of making clinical practice guidelines and discussion on their social impacts. (2) Evidence-based practical guideline for the treatment of diabetes in Japan. Nihon Naika Gakkai Zasshi 2013; 102: 2291-5. (Japanese)

23. Goldstein JL, Schrott HG, Hazzard WR, Bierman EL, Motulsky AG. Hyperlipidemia in coronary heart disesase. II. Genetic analysis of lipid levels in 176 families and delineation of a new inherited disorder, combined hyperlipidemia. J Clin Invest 1973; 52: 154468.

24. De Backer G, Besseling J, Chapman J, et al; EUROASPIRE Investigators. Prevalence and management of familial hypercholesterolemia in coronary patients: An analysis of EUROASPIRE IV, a study of the European Society of Cardiology. Atherosclerosis 2015; 241: 169-75.

25. Palacios L, Grandoso L, Cuevas N, et al. Molecular characterization of familial hypercholesterolemia in Spain. Atherosclerosis 2012; $221: 137-42$

26. Sullivan D. Guidelines for the diagnosis and management of familial hypercholesterolaemia. Heart Lung Circ 2007; 16: 25-7.

27. Lehtonen A, Mäkelä P, Viikari J, Virtama P. Achilles tendon thickness in hypercholesterolaemia. Ann Clin Res 1981; 13: 39-44.

28. Schmidt HH, Hill S, Makariou EV, Feuerstein IM, Dugi KA, Hoeg JM. Relation of cholesterol-year score to severity of calcific atherosclerosis and tissue deposition in homozygous familial hypercholesterolemia. Am J Cardiol 1996; 77: 575-80.

29. Civeria F, Castill S, Alonso R, et al; Spanish Familial Hypercholesterolemia Group. Tendon xanthomas in familial hypercholester- 
olemia are associated with cardiovascular risk independently of the low-density lipoprotein receptor gene mutation. Arterioscler Thromb Vasc Biol 2005; 25: 1960-5.

30. Oosterveer DM, Versmissen J, Yazdanpanah M, Hamza TH, Sijbrands EJ. Differences in characteristics and risk of cardiovascular disease in familial hypercholesterolemia patients with and without tendon xanthomas: a systematic review and meta-analysis. Atherosclerosis 2009; 207: 311-7. (Review)

31. Sugisawa T, Okamura T, Makino H, et al. Defining patients at extremely high risk for coronary artery disease in heterozygous familial hypercholesterolemia. J Atheroscler Thromb 2012; 19: 36975.

32. Primary Panel: Genest J, Hegele RA, Bergeron J, et al. Canadian Cardiovascular Society position statement on familial hypercholesterolemia. Can J Cardiol 2014; 30: 1471-81. (Review)

33. Nair DR, Sharifi M, Al-Rasadi K. Familial hypercholesterolaemia. Curr Opin Cardiol 2014; 29: 381-8. (Review)

34. Weng SF, Kai J, Andrew Neil H, Humphries SE, Qureshi N. Improving identification of familial hypercholesterolaemia in primary care: Derivation and validation of the familial hypercholesterolaemia case ascertainment tool (FAMCAT). Atherosclerosis 2015; 238: 336-43.

35. Singh S, Bittner V. Familial hypercholesterolemia — epidemiolo- gy, diagnosis, and screening. Curr Atheroscler Rep 2015; 17: 482. (Review)

36. Feldman DI, Blaha MJ, Santos RD, et al. Recommendations for the management of patients with familial hypercholesterolemia. Curr Atheroscler Rep 2015; 17: 473. (Review)

37. Fukuzawa S, Ozawa S, Inagaki M, Morooka S, Inoue T. Secondary prevention with lipid lowering therapy in familial hypercholesterolemia: a correlation between new evolution of stenotic lesion and achieved cholesterol levels after revascularization procedures. Intern Med 1999; 38: 330-5.

38. Masaki N, Tatami R, Kumamoto T, et al. Ten-year follow-up of familial hypercholesterolemia patients after intensive cholesterollowering therapy. Int Heart J 2005; 46: 833-43.

39. Vermissen J, Oosterveer DM, Yazdanpanah M, et al. Efficacy of statins in familial hypercholseterolaemia: a long term cohort study. BMJ 2008; 337: a2423.

40. Yamashita S, Bujo H, Arai H, et al. Long-term probucol treatment prevents secondary cardiovascular events: a cohort study of patients with heterozygous familial hypercholesterolemia in Japan. J Atheroscler Thromb 2008; 15: 292-303.

41. Harada-Shiba M, Sugisawa T, Makino H, et al. Impact of statin treatment on the clinical fate of heterozygous familial hypercholesterolemia. J Atheroscler Thromb 2010; 17: 667-74. 